\title{
Degradable Polystyrene via the Cleavable Comonomer Approach
}

\author{
Noémie Gil, ${ }^{1}$ Baptiste Caron, ${ }^{1}$ Didier Siri, ${ }^{1}$ Julien Roche, ${ }^{2}$ Slim Hadiouch, ${ }^{1}$ Douriya Khedaioui, ${ }^{3}$ \\ Stéphane Ranque, ${ }^{2}$ Carole Cassagne, ${ }^{2}$ Damien Montarnal, ${ }^{3}$ Didier Gigmes, ${ }^{1}$ Catherine Lefay, ${ }^{1, *}$ \\ Yohann Guillaneuf ${ }^{1, *}$ \\ ${ }^{1}$ Aix-Marseille Univ, CNRS, Institut de Chimie Radicalaire, UMR 7273, F-13397 Marseille, France. \\ ${ }^{2}$ Aix Marseille Univ, APHM, IHU Méditerranée Infect, IRD, VITROME, Marseille, France \\ ${ }^{3}$ Univ. Lyon, CPE Lyon, CNRS, Catalyse, Polymerization, Processes and Materials, UMR 5128, F-69003 Lyon, France
}

\begin{abstract}
Polystyrene (PS) is a major commodity polymer, widely used in various applications ranging from packaging to insulation thanks to its low cost, high stiffness and transparency as well as its relatively high softening temperature. Similarly to all polymers prepared by radical polymerization, PS is constituted of a C-C backbone and thus is not degradable. To confer degradability to such materials, the copolymerization of vinyl monomers with cyclic monomer that could undergo radical ring-opening is an efficient methodology to introduce purposely cleavable bonds into the polymer backbone. Dibenzo[c,e]-oxepane-5-thione (DOT) is a cyclic thionolactone monomer known for its efficient copolymerization with acrylate derivatives but so far could not be incorporated into PS backbones. From a theoretical study combining DFT and kinetic models using the PREDICI software, we showed that modifying experimental conditions could overcome these limitations and that high molar mass degradable polystyrene $\left(M_{\mathrm{w}}\right.$ close to 150,000 g.mol $\left.{ }^{-1}\right)$ could be prepared via statistical insertion of thioester groups into the polymer backbone. Thanks to favorable reactivity ratios allowing only a few mol\% of thioester units to be randomly incorporated, there was no major modification of the thermal and mechanical properties of the PS. The degradation of such PS could be performed in THF at RT in one hour using 1,5,7-triazabicyclo[4.4.0]dec-5-ene (TBD) as a base, leading to oligomers with $M_{\mathrm{n}}$ close to 1,00o g.mol ${ }^{-1}$. We successfully demonstrate further applicability of these copolymerization systems for the photo-triggered decomposition of PS in solution as well as the synthesis of crosslinked PS networks degradable into soluble side-products.
\end{abstract}

\section{Introduction}

Plastic waste has become a global environmental concern, with more than 300 million tons of petroleum-based synthetic plastics industrially produced worldwide every year. Polystyrene (PS) is one of the major sources of plastic products in the world. Due to its high durability, easy processability and hydrolytic stability, PS is widely used in packaging, insulation, building and food processing industries and thus has become a major pollutant of soils, rivers, lakes, and oceans. ${ }^{1}$

The most common chemical approach to recycle polystyrene waste is thermal or thermocatalytic decomposition that leads either to fuel-like products ${ }^{2}$ or to close-loop recycling through the recovery of styrene monomer ${ }^{3}$. Another route of recycling for PS, particularly suited for foams, proceeds through the dissolution of waste ${ }^{4}$ in solvents ${ }^{5}$ (including terpenics such as limonene) followed by recovery in supercritical $\mathrm{CO}_{2}$. Biodegradation of plastic waste, including that of PS, has been studied since the 1960's. Researchers have attempted to use mixed microbial cultures and have isolated bacteria from various sources such as soil, garbage or sewage sludge to biodegrade various plastics into low molecular organics or mineralize to
$\mathrm{CO}_{2}$. The ability of microorganisms to use polystyrene as a carbon source has been recently established. ${ }^{6-8}$ However, the high molar mass of commercial PS severely limits the efficiency of these enzymatic reactions.

The convenience and the increasing demand for these polymers despite the environmental concerns are strong incitements to convert PS into (bio)degradable materials. A possible solution is to use, in a first degradation step, an additive capable of accelerating the cleavage of the long $\mathrm{C}$ $\mathrm{C}$ backbone, followed in a second step by classic biodegradation of short oligomers. Radical ring-opening polymerization (rROP) combines both the advantages of ring-opening polymerization and radical polymerization, that is the production of polymers having heteroatoms and/or functional groups in the main chain together with the robustness, the ease of use and the mild polymerization conditions of a radical process (Scheme 1). ${ }^{9}$ The polymerization occurs via the addition of radicals onto cyclic monomers bearing an exo-methylene function or equivalent groups followed by a fragmentation of the intermediate cyclic radical to afford a new radical and the incorporation of heteroatoms into the $\mathrm{C}-\mathrm{C}$ backbone. 

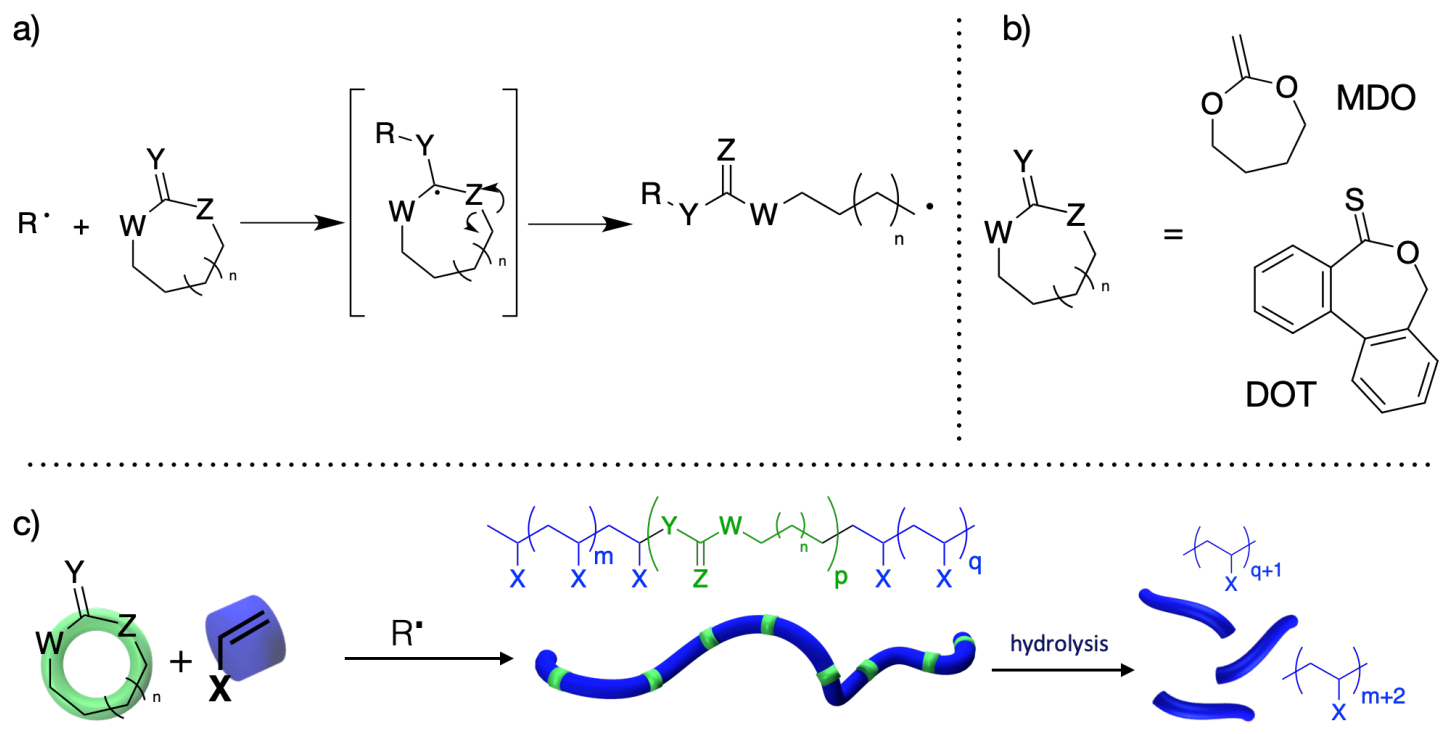

Scheme 1. a) Radical addition/fragmentation mechanism. b) Structure of the MDO and DOT monomers. c) Insertion of hydrolytically cleavable bonds into polymer backbone by the radical ring-opening copolymerization technique.

Cyclic ketene acetals (CKA) were reported by Bailey and coworkers in the 8o's as suitable monomers for rROP. ${ }^{9-11}$ This monomer family was then extensively studied as a way to produce polymers similar to classic aliphatic polyesters, but through a radical pathway. This technique has been recently rejuvenated by the possibility to copolymerize CKA with classic vinyl monomers, enabling the introduction of cleavable functions into the copolymer backbone. This led to a broad range of novel (bio)degradable polymers suitable for a large scope of applications. ${ }^{9}$, 10 Among the various CKAs, 2-methylene-1,3-dioxepane (MDO) and 5,6-benzo-2-methylene-1,3-dioxepane (BMDO) were the most studied and used monomers thanks to their very efficient ring-opening ability. The main limitation of such polymerization process is related to the specific reactivity of the CKA compared to common vinyl monomers. In particular, the copolymerization of CKA and styrene is hardly performed in the literature due to unfavored reactivity ratios (Bailey et al. ${ }^{12}$ reported values of $r_{\mathrm{MDO}}=0.021$ and $r_{\mathrm{sty}}=22.6 \mathrm{in}$ bulk at $120^{\circ} \mathrm{C}$ and Aggarwal et al. ${ }^{13} r_{\mathrm{BMDO}}=1.08$ and $r_{\text {sty }}=8.53$ in bulk using ATRP at 120 $\left.{ }^{\circ} \mathrm{C}\right)$. With these values, an initial fraction of $80 \mathrm{~mol} \% \mathrm{MDO}$ leads to a PS with only $12 \mathrm{~mol} \%$ of ester units. ${ }^{14}$ The high discrepancy between the reactivity of the two monomers could led to very heterogenous materials, as recently highlighted by Thoniyot et al. ${ }^{14}$ Moreover, our group recently showed by a theoretical approach that such unfavorable reactivity ratios led to heterogeneous degradations with some chains being only slightly affected. ${ }^{15}$

To circumvent such drawbacks, Roth and coworkers ${ }^{16}$ followed by Gutekunst et al. ${ }^{17}$ recently proposed thionolactones as new cyclic monomers for rROP. In particular they both showed that dibenzo[c,e]-oxepane-5-thione (DOT) is able to copolymerize with acrylate derivatives, acryloni- trile and $N, N$-dimethylacrylamide and thus enables the insertion of thioester functionalities into the polymer backbone in a efficiently manner. The thioester linkages that were inserted into the polymer chain confer degradability by both basic hydrolysis, ${ }^{18}$ aminolysis ${ }^{16}$ (e.g. using isopropylamine in dichloromethane), oxidative hydrolysis, ${ }^{18}$ and methanolysis ${ }^{17}$. Nevertheless, both studies claimed that these new monomers cannot homopolymerize nor copolymerize with styrene. ${ }^{16,17}$ In the latter case, only polystyrene is obtained with DOT remaining spectator. Since these preliminary studies, we sought to understand the peculiar reactivity of thionolactone derivatives, and in particular of the DOT monomer.

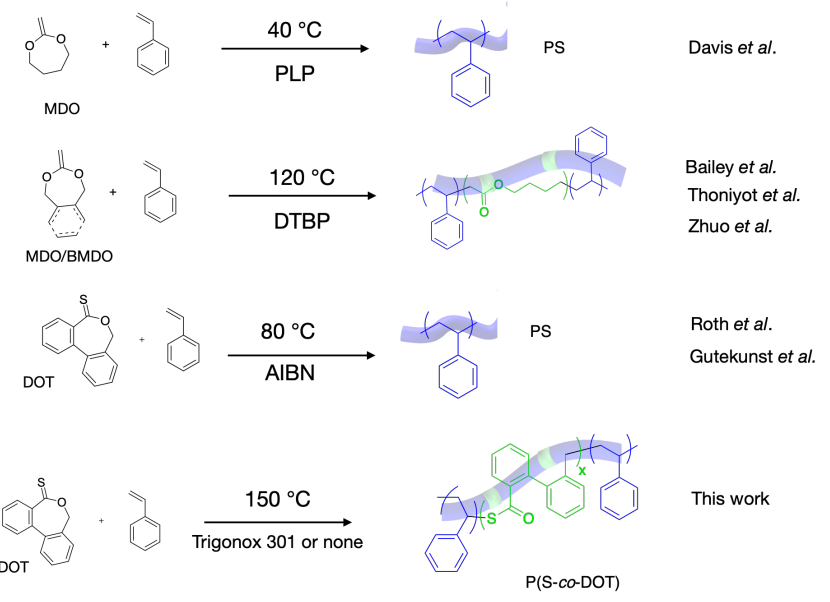

Scheme 2. Preparation of degradable polystyrene by the radical ring opening copolymerization of cyclic rROP monomers and styrene.

Starting from a theoretical study combining both quantum chemistry (DFT calculations) and numerical modeling using the PREDICI software, we describe in this work that 
the copolymerization of DOT with styrene works well provided that high temperatures are used, and that statistical copolymers can be obtained.

We illustrate the wide possibilities that arise by synthesizing high molar mass copolymers of styrene and DOT, with only minor modification of properties, but amenable to complete degradation (Scheme 2). A comparison study with CKA monomers (MDO and BMDO) was also performed showing the impact of the reactivity ratios on the degradation of the polymers. Random incorporation of such DOT comonomers is thus an efficient manner to introduce cleavable bonds inside the PS backbone and we will highlight its impact on the degradability of the resulting materials.

\section{Results and discussion}

\section{Preparation of PS- Co-CKA and PS-Co-DOT}

The aim of this work is to investigate the preparation of degradable polystyrene via the copolymerization of styrene and cyclic monomers. We thus started by performing the copolymerization of styrene with MDO using experimental conditions recently reported by Thoniyot and coworkers. ${ }^{14}$ The polymerizations were performed initially at $120^{\circ} \mathrm{C}$ with an optimized reaction time to avoid compositional drift (Table 1). Initial feed ratio in MDO was 20 $\mathrm{mol} \%$ and $1 \mathrm{~mol} \%$ of di-tert-butyl peroxide (DTBP) was used as the initiator. After 6 hours, a PS with a $M_{\mathrm{n}}$ of 67,300 g.mol ${ }^{-1}$ and a $Ð$ of 2.2 was obtained. The analysis of the purified copolymer showed that only $3 \mathrm{~mol} \%$ of MDO units was inserted into the backbone, in rather good agreement with Thoniyot et al. ${ }^{14}$ This copolymer was degraded using accelerated conditions $(\mathrm{KOH} 5 \mathrm{wt} \%$ in THF/MeOH for 96 h) leading to degraded products of $M_{\mathrm{n}}=12,8 \mathrm{oog}$ g.mol ${ }^{-1}$ and $\nexists$ of 2.9. To decrease the length of the degraded products, a similar experiment was performed with a MDO initial feed ratio of $50 \mathrm{~mol} \%$. In that case, due to a lower concentration of styrene, the $M_{\mathrm{n}}$ decreased to $45,800 \mathrm{~g} \cdot \mathrm{mol}^{-1}$ with a $Ð$ of 1.9.

Table 1. PS containing either MDO or DOT comonomer before and after degradation

\begin{tabular}{ccccc}
\hline & $\begin{array}{c}\text { Ratio } \\
\text { S/Comono } \\
\text { mer }\end{array}$ & $\begin{array}{c}\text { Comono } \\
\text { mer }\end{array}$ & $\begin{array}{c}M_{\mathrm{n}}(\Theta) \text { before } \\
\text { degradation } \\
\text { g.mol }\end{array}$ & $\begin{array}{c}M_{\mathrm{n}}(\Theta) \text { after } \\
\text { degradation } \\
\text { g.mol }\end{array}$ \\
\hline $\mathbf{P}^{\mathrm{a}, \mathrm{b}}$ & $80 / 20$ & MDO & $67,300(2.2)$ & $\begin{array}{c}12,800 \\
(2.9)\end{array}$ \\
$\mathbf{P 2}^{\mathrm{a}, \mathrm{b}}$ & $50 / 50$ & MDO & $45,800(1.9)$ & $5,400(2.3)$ \\
$\mathbf{P 3}^{\mathrm{a}, \mathrm{c}}$ & $50 / 50$ & MDO & $90,000(2.0)$ & $6,300(2.0)$ \\
$\mathbf{P 4}^{\mathrm{d}, \mathrm{e}}$ & $95 / 5$ & DOT & $7,800(1.8)$ & $3,000(2.1)$ \\
$\mathbf{P}^{\mathrm{d}, \mathrm{e}}$ & $70 / 30$ & DOT & $4,500(1.5)$ & - \\
$\mathbf{P 6}^{\mathrm{d}, \mathrm{e}}$ & $50 / 50$ & DOT & $3,000(1.5)$ & - \\
$\mathbf{P 7}^{\mathrm{d}, \mathrm{f}}$ & $95 / 5$ & DOT & $16,300(2.0)$ & $2,500(1.9)$ \\
\hline
\end{tabular}

${ }^{\mathrm{a}}$ bulk, $120{ }^{\circ} \mathrm{C},{ }^{\mathrm{b}} 1 \mathrm{~mol} \%$ DTBP, ${ }^{\mathrm{c}} \mathrm{o.1} \mathrm{mol} \%$ DTBP, ${ }^{\mathrm{d}} 80{ }^{\circ} \mathrm{C}, 1$ mol\% AIBN, ${ }^{\mathrm{e}} 80 \mathrm{~mol} \%$ anisole, ${ }^{\mathrm{f}}$ $10 \mathrm{~mol} \%$ anisole
Nevertheless, the amount of ester units increased to 6 $\mathrm{mol} \%$ and led to degraded product of $M_{\mathrm{n}}=5,400 \mathrm{~g} \cdot \mathrm{mol}^{-1}$ and $\oslash$ of 2.3. To increase the $M_{\mathrm{n}}$ of the initial polymer, a lower amount of initiator ( $0.1 \mathrm{~mol} \%)$ could be used but at the expense of the overall conversion (7o instead of $85 \%$ ).

Since it is not possible to degrade the copolymers into oligomers of less than 5,000 g. mol ${ }^{-1}$, we thus investigated the use of DOT as comonomer in the polymerization of styrene. Indeed, this comonomer pair was only hardly investigated previously. ${ }^{16,17}$ We started with the experimental conditions used by Roth and coworkers ${ }^{16}\left(80{ }^{\circ} \mathrm{C}\right.$, anisole with only $20 \mathrm{~mol} \%$ of monomers since the DOT is hardly soluble in common vinyl monomers) and tested 3 initial feed ratio, i.e $[\mathrm{S}]_{\mathrm{o}}:[\mathrm{DOT}]_{\mathrm{o}}=95: 5,70: 30$ and 50:50. With the lowest amount of DOT ( $5 \mathrm{~mol} \%)$, the conversion of styrene reached only $50 \%$ after $24 \mathrm{~h}$ and produced a PS with a $M_{\mathrm{n}}$ of 7,800 g.mol ${ }^{-1}$. With higher DOT amount, $f_{\mathrm{DOT}, 0}=30$ and $50 \mathrm{~mol} \%$, the conversion lowered to 35 and $25 \%$ and the $M_{\mathrm{n}}$ decreased to 4,500 and 3,000 g.mol ${ }^{-1}$, respectively, impeding its practical use to prepare high molecular weight polystyrene. The experiment with $f_{\mathrm{DOT}, \mathrm{o}}=5 \mathrm{~mol} \%$ was then investigated in more details. The kinetics of the copolymerization is shown in the ESI Figure S1, with the conversion of DOT being half the conversion of styrene. This led to an incorporated amount of DOT inside the backbone close to $2.5 \mathrm{~mol} \%$. The isolated copolymer was degraded using different accelerated conditions, that is $\mathrm{KOH}_{5} \mathrm{wt} \%$ in THF/MeOH, $\mathrm{N}$-isopropylamine $50 \mathrm{wt} \%$ in DCM and 1,5,7-triazabicyclo[4.4.0]dec-5-ene (TBD) $2.5 \mathrm{wt} \%$ in THF. We obtained a degraded product with a $M_{n}$ close to 3,000 g.mol ${ }^{-1}$ (Figure 1).

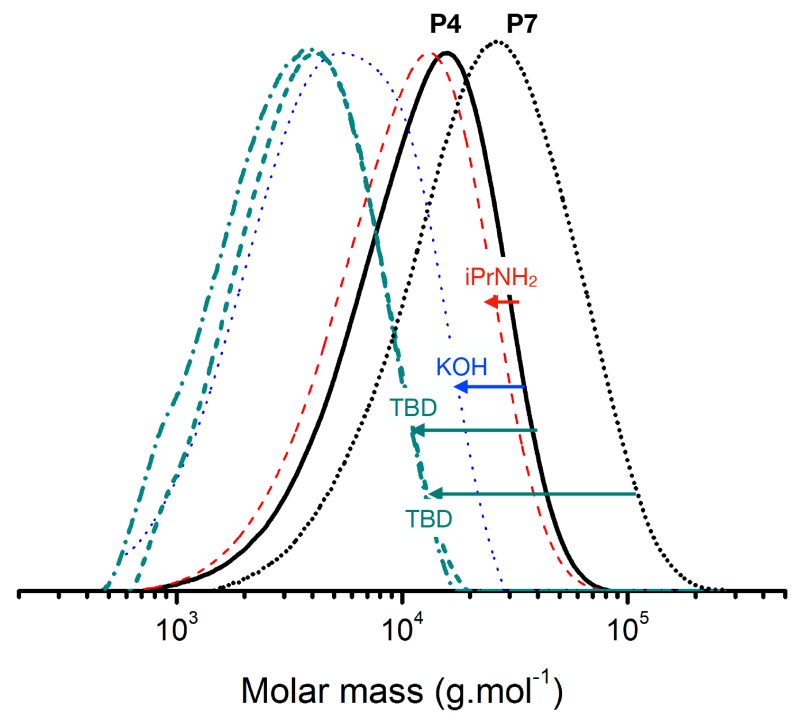

Figure 1. Molar mass distribution of $\mathrm{P}(\mathrm{S}$-co-DOT) before and after degradation: $\mathbf{P}_{\mathbf{4}}$ before degradation (solid line dark), $\mathbf{P}_{\mathbf{7}}$ before degradation (short-dotted line dark), $\mathbf{P}_{\mathbf{4}}$ after $18 \mathrm{~h}$ of degradation using $\mathrm{iPrNH}_{2}$ in DCM (dashed line red), $\mathbf{P} 4$ after $18 \mathrm{~h}$ of degradation using $5 \mathrm{wt} \% \mathrm{KOH}$ in $\mathrm{THF} / \mathrm{MeOH}$ (dotted line blue), $\mathbf{P}_{4}$ after $18 \mathrm{~h}$ of degradation using $2.5 \mathrm{wt} \% \mathrm{TBD}$ in THF (short-dashed line cyan) and $\mathbf{P}_{7}$ after $18 \mathrm{~h}$ of degradation using $2.5 \mathrm{wt} \%$ TBD in THF (dashed dotted line cyan). 
It has to be noted that the aminolysis conditions did not lead to degradation unlike it usually occurs for thioester moieties into polyacrylate and polyacrylamide derivatives. $^{16-18}$ On the contrary, the use of TBD revealed to be very efficient (the kinetics and different mode of degradation are detailed in the degradation paragraph). Since only $5 \mathrm{~mol} \%$ of DOT is used, we thus decreased the amount of anisole to improve the kinetics and the length of the polystyrene while keeping the DOT soluble. By using $10 \mathrm{~mol} \%$ of anisole instead of $80 \mathrm{~mol} \%$ used previously, we obtained in two hours $70 \%$ of conversion for the styrene and close to $40 \%$ for the DOT, producing a PS with $M_{n}$ of 16,250 g. $\mathrm{mol}^{-1}$ incorporating $3 \mathrm{~mol} \%$ of thioester units. The degradation using TBD led to oligomers of $M_{n}=2,500 \mathrm{~g} . \mathrm{mol}^{-1}$ (Figure 1). A similar degradation product is obtained showing that the incorporation of the DOT is identical to the previous experiment and only the $M_{\mathrm{n}}$ of the polymer before degradation changed with a decrease amount of solvent. These results showed that unlike the results of both Gutekunst ${ }^{17}$ and Roth, ${ }^{16}$ the copolymerization of DOT and styrene occurred even though only half of the thioester units were successfully incorporated into the backbone. Secondly, at higher DOT amount, the lower reactivity and the solvent that is necessary to dissolve it impedes its use in copolymerization with styrene at high ratio. Such behavior is thus different to the one of acrylate and acrylamides derivatives and this difference will be studied by quantum chemistry.

\section{Theoretical considerations}

As discussed previously, the radical copolymerization of DOT monomer with acrylate derivatives was reported to be efficient, with a statistical incorporation of the thioester functionality inside the vinyl-based backbone. ${ }^{16,}{ }^{17}$ In contrast, copolymerization with styrene led only to the preparation of polystyrene without incorporation of the thionolactone into the backbone.

To have a better understanding of this phenomenon, DFT calculations were performed to determine the enthalpies of reaction as well as the activation energies of $i$ ) the addition of alkyls radicals onto the thionolactone functionality and ii) the $\beta$-scission of the intermediate radical that either leads to thioester and a second released alkyl radical or
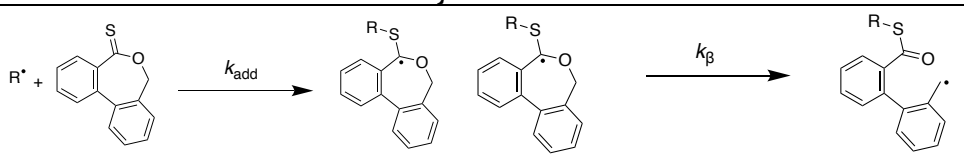

$E_{\mathrm{a}, \text { add }}\left(\mathrm{kJ} \mathrm{mol}^{-1}\right) \quad \Delta \mathrm{Hr}\left(\mathrm{kJ} \mathrm{mol}^{-1}\right)$

$E_{\mathrm{a}, \beta}\left(\mathrm{kJ} \mathrm{mol}^{-1}\right)$ gives back the thionolactone and the propagating vinyl macroradical (Scheme 3).To perform such theoretical study, we choose the UB3LYP/6-31G(d) level of theory due to the large number of atoms that are involved in the system. Moreover we already showed that this level of theory allowed us to have a good understanding of the homopolymerization of $\mathrm{CKA}^{19}$ or the copolymerization behavior of CKA with various vinyl monomers. ${ }^{20,21}$

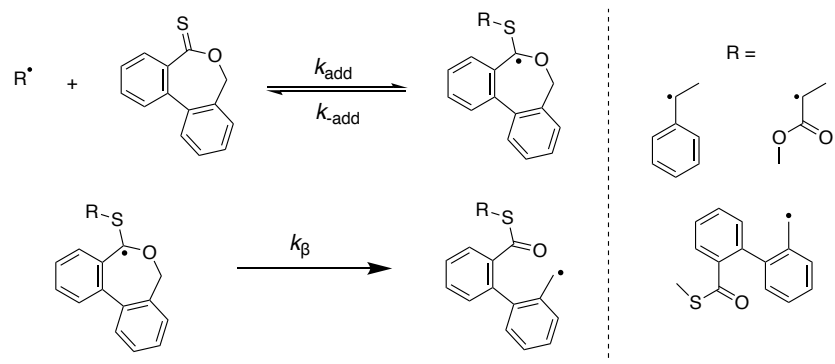

Scheme 3. Kinetic scheme that has been theoretically investigated by DFT calculations.

In such previous study, more complex level of theory (G3MP2RAD, BMK, etc.) led to similar results but with increased computational time. ${ }^{19,}{ }^{20,22}$ The results of the calculations are gathered in Table 2. We can first observe that the $\beta$-scission reaction of the radical intermediate is not affected by the nature of the radical adduct since both enthalpies of reaction $\Delta \mathrm{H}_{\mathrm{r}}$ and activation energies are rather similar (close to $-23 \mathrm{~kJ} \mathrm{~mol}^{-1}$ for $\Delta \mathrm{H}_{\mathrm{r}}$ and close to $60 \mathrm{~kJ} \mathrm{~mol}^{-}$ ${ }^{1}$ for the $\left.E_{\mathrm{a}, \beta}\right)$. The main difference evidenced from the calculations is the higher activation energy for the addition onto DOT monomers of styryl or DOT-based radicals $\left(E_{\mathrm{a}, \text { add }}\right.$ close to $\left.28 \mathrm{~kJ} \mathrm{~mol}^{-1}\right)$ than of acrylate radicals $\left(E_{\mathrm{a}, \mathrm{add}}=\right.$ $12 \mathrm{~kJ} \mathrm{~mol}^{-1}$ ). This results in the more favorable addition of acrylate derivatives during the copolymerization and thus could explain a better statistical incorporation of DOT in such copolymerization system. In the case of styrene, the calculations showed that the addition-fragmentation mechanism is still possible but should be favored at higher temperature. A qualitative assessment of the copolymerization behavior can be obtained through the determination of transfer rate constant, by analogy with methods developed for kinetics of RAFT polymerization.

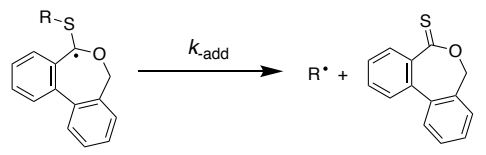

$\Delta \mathrm{Hr}\left(\mathrm{kJ} \mathrm{mol}^{-1}\right)$

$E_{\mathrm{a}, \text {-add }}\left(\mathrm{kJ} \mathrm{mol}^{-1}\right) \quad \Delta \mathrm{Hr}\left(\mathrm{kJ} \mathrm{mol}^{-1}\right)$

\begin{tabular}{|c|c|c|c|c|c|c|}
\hline 7 & 29 & -14.6 & 62.6 & -23.1 & 41.2 & 14.6 \\
\hline & 11.7 & -26.5 & 58.8 & -22.1 & 35.8 & 26.5 \\
\hline & 27.3 & -22.4 & 61.5 & -23.8 & 47.3 & 22.4 \\
\hline
\end{tabular}

Table 2. Energies of activation and enthalpies of reaction for the different radical addition on the DOT monomer and the $\beta$ scission of the intermediate radical. 
This complex rate constant allows the estimation of the efficiency of a RAFT agent by taking into account the combination of the radical addition ( $a d d)$, inverse radical addition (-add) and $\beta$-scission reaction $(\beta)$ that occurred during the RAFT process. ${ }^{23}$ The transfer rate constant is given by the following equation:

$$
k_{t r}=k_{a d d} \times \frac{k_{\beta}}{k_{-a d d}+k_{\beta}}
$$

This rate coefficient could then be compared to the propagation rate constant of the vinyl monomer to estimate the copolymerizability of the two monomer pairs. To determine the kinetic rate constants, we have to calculate or estimate the Arrhenius pre-exponential factor. It is known that the DFT calculation of such entropy-based parameter is difficult due to the treatment of all vibrations as harmonic oscillators. ${ }^{24}$

While the entropy associated for certain vibrations is correct, hindered rotations occurring in cyclic molecules cannot be properly taken into account. We rather opted for conservative estimations of the pre-exponential factors using previously reported values. ${ }^{19,22}$ This approach was experimentally validated with cyclic ketene acetals. ${ }^{19,22}$ In particular for radical addition reaction, we used $\mathrm{A}_{\mathrm{add}}=10^{8}$ $\mathrm{L} \mathrm{mol}^{-1} \mathrm{~s}^{-1}$ for secondary radical as recommended by Fischer and Radom. ${ }^{25}$ For the unimolecular $\beta$-fragmentation, a value of $A_{\beta}=10^{13} \mathrm{~s}^{-1}$ was used. ${ }^{26-28} A$ similar value is also used for the reverse addition rate constant $A_{\text {-add }}=10^{13} \mathrm{~s}^{-1}$. The results for each rate coefficient and transfer coefficient are summarized in Table 3 as well as the influence of the temperature on such values. Experimentally, both Roth ${ }^{16}$ and Gutekunst ${ }^{17}$ showed good incorporation of thionolactones with acrylate derivatives at $80^{\circ} \mathrm{C}$. With such monomers, the ratio between $k_{\mathrm{p}}$ and $k_{\mathrm{tr}}$ is close to 13 . With styrene, this ratio is higher (above 30 ) showing a lower reactivity of DOT with styrene. Nevertheless, by increasing the temperature up to $150^{\circ} \mathrm{C}$, the value reached the threshold value of 19 that is closer to the one determined for acrylate derivatives copolymerization at $80{ }^{\circ} \mathrm{C}$. Such conditions seemed thus more compatible with a good copolymerization behavior between styrene and DOT.

Table 3. Theoretical calculation of the transfer rate constant $k_{\text {tr }}$ as defined in equation 1 and the ratio between this constant and the propagation rate constant $k_{\mathrm{p}}$ of styrene and acrylate derivatives

\begin{tabular}{|c|c|c|c|}
\hline & $80^{\circ} \mathrm{C}$ & $120^{\circ} \mathrm{C}$ & $150^{\circ} \mathrm{C}$ \\
\hline $\begin{array}{c}k_{\mathrm{tr}}(\text { acrylate on DOT }), \\
\mathrm{kJ} \mathrm{mol}^{-1}\end{array}$ & 737 & 2452 & 5201 \\
\hline $\begin{array}{c}k_{\mathrm{p}} / k_{\mathrm{tr}} \\
\text { (acrylate on DOT) }\end{array}$ & 13 & 10 & 8.5 \\
\hline $\begin{array}{c}k_{\mathrm{tr}}(\text { styrene on DOT), } \\
\mathrm{kJ} \mathrm{mol}^{-1}\end{array}$ & 3.5 & 20.2 & 60.3 \\
\hline $\begin{array}{c}k_{\mathrm{p}} / k_{\mathrm{tr}} \\
\text { (styrene on DOT) }\end{array}$ & 33 & 23 & 19 \\
\hline
\end{tabular}

To go a step further, kinetic modellings using the PREDICI software were performed to have a better idea of the copolymerization behavior.

\section{Kinetic simulations}

DFT calculations were interesting to understand the behavior of the radical processes, but, due to too many assumptions, cannot describe macroscopically the results of the polymerization. To do this, we first tried to simulate the polymerization using a simplified copolymerization kinetic scheme using the PREDICI software. ${ }^{29}$ In this scheme, the main adjustable parameters are the reactivity ratios $r_{\mathrm{S}}$ and $r_{\mathrm{DOT}}$ as well as the propagation rate constant of the DOT homopolymer. (the details of the model and its validation on homopolymerization of styrene are presented in ESI, Figure $\mathrm{S}_{2}$ ). We could fit the experimental conversion of the DOT/S copolymerization at $80^{\circ} \mathrm{C}$ with a feed ratio of $[\mathrm{S}]_{\mathrm{o}}:[\mathrm{DOT}]_{\mathrm{o}}=95: 5$ with a $r_{\mathrm{S}}=2.0$, a $r_{\mathrm{DOT}}=0.36$ and a $k_{\mathrm{p}, \mathrm{DOT}}=30 \mathrm{~L} \cdot \mathrm{mol}^{-1} \cdot \mathrm{s}^{-1}$ (Figure 2).

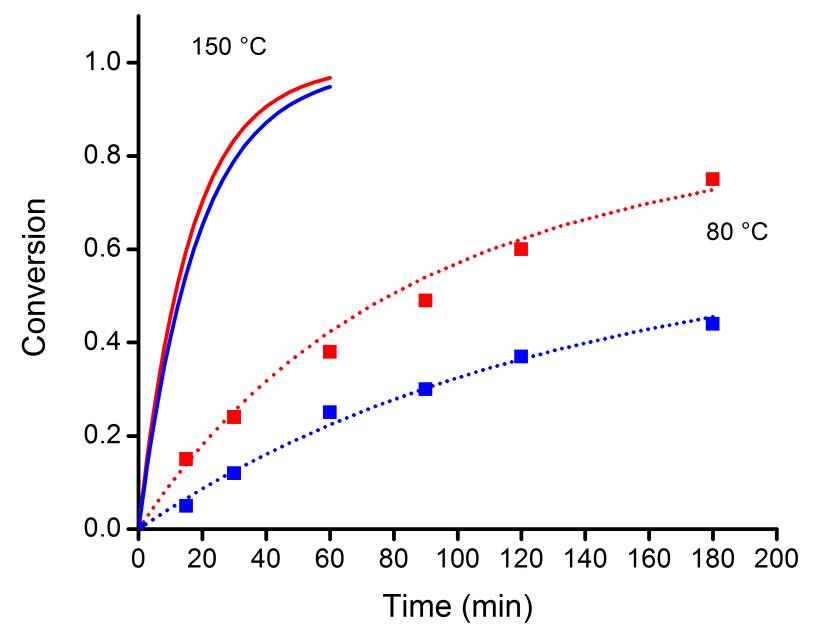

Figure 2. Kinetic plot of the experimental copolymerization of styrene (red squares) and DOT (blue squares) at $80^{\circ} \mathrm{C}$ in presence of anisole (10 mol\%) with feed ratio [Styrene] : $[D O T]_{0}=95: 5$. The dashed lines are the PREDICI fits using $r \mathrm{~s}=2.0, r \mathrm{DOT}=0.36$ and $k_{\mathrm{p}, \mathrm{DOT}}=30 \mathrm{~L} \cdot \mathrm{mol}^{-1} \cdot \mathrm{s}^{-1}$. The solid lines are the corresponding PREDICI simulations at $150^{\circ} \mathrm{C}$, assuming that the kinetic parameters follow a pseudo-Arrhenius behavior and $E_{\mathrm{a}}$ values determined by DFT calculations.

The reactivity ratios values obtained are interesting since they can be compared to the $k_{\text {tr }}$ values that were previously calculated via DFT calculations. In this approach, $k_{\mathrm{p}} / k_{\mathrm{tr}}$ is equals to $r_{\mathrm{S}}$ and the experimental value is one order of magnitude lower than the calculated one (2.0 instead of 33). This is in rather good agreement with the assumption of a gas phase and the pre-exponential factors that were only approximated according to the nature of the reaction. Nevertheless, the main interest of the DFT calculations combined with PREDICI simulations relies on the determination of the activation energies that could help us to find optimized experimental temperature. We thus performed also DFT calculations to determine the activation energies and also $k_{\text {tr }}$ between the open form of the DOT radical onto the DOT. This allows us to estimate the $k_{\mathrm{p}, \mathrm{DOT}}$ 
and the addition of the open form of the DOT radical onto styrene to determine the $r_{\mathrm{DOT}}$ value (the details of these calculations are given in ESI). The interesting feature relies on the pseudo-Arrhenius dependency of the two reactivity ratio values. The $r_{\mathrm{S}}$ has a $-10 \mathrm{~kJ} \cdot \mathrm{mol}^{-1}\left(E_{\mathrm{a}, \mathrm{p}}-\left(E_{\mathrm{a}, \mathrm{add}}+E_{\mathrm{a} \beta}-E_{\mathrm{a} \text {,-add }}\right)\right)$ whereas the $r_{\text {DOт }}$ has a $16 \mathrm{~kJ} \cdot \mathrm{mol}^{-1}$ dependance, meaning that increasing the temperature will lead to bring the two reactivity ratios closer to the value 1 and thus should lead to better incorporation of the two comonomers into the backbone. By using the value determined by fitting and used the calculated pseudo-Arrhenius behavior, we simulated the copolymerization of styrene and DOT with $f_{\mathrm{s}, \mathrm{o}}$ $=0.95$ at $150^{\circ} \mathrm{C}$ in $10 \%$ anisole (Figure 2 ). In that case, simulated $r_{\mathrm{S}}$ and $r_{\text {DOT }}$ were set to 1.14 and 0.88 , with $k_{\mathrm{p}, \mathrm{DOT}}=$ $500 \mathrm{~L} . \mathrm{mol}^{-1} . \mathrm{s}^{-1}$. The results presented in Figure 2 confirm the better copolymerization behavior with rather similar conversion for both styrene and DOT.

\section{Optimized preparation of $\mathrm{P}(\mathrm{S}-\mathrm{Co}-\mathrm{DOT})$ at $150^{\circ} \mathrm{C}$}

The previous theoretical studies comforted us in performing the copolymerization of DOT and styrene at high temperature $\left(150^{\circ} \mathrm{C}\right)$. At this temperature, we used either a peroxide as initiator (Trigonox 301) or the thermal autopolymerization of styrene. The copolymerizations were also carried out with initial feed ratios $[\mathrm{S}]_{0}:[\mathrm{DOT}]_{\mathrm{o}}$ of 95 : 5 and $80: 20$ to investigate the influence of DOT content on the degradability of the copolymers. To perform the polymerization with $20 \mathrm{~mol} \%$ of DOT, $8 \mathrm{o} \mathrm{mol} \%$ of anisole to ensure the good solubility of DOT (i.e. $\left.\left.[\mathrm{S}]_{\mathrm{o}}:[\mathrm{DOT}]_{\mathrm{o}}:[\text { Anisole }]_{\mathrm{o}}=8: 2: 4 \mathrm{O}\right]\right)$ was still used for the two experiments. The resulting $\mathrm{P}(\mathrm{S}-\mathrm{co}-\mathrm{DOT})$ copolymers were isolated and analyzed by ${ }^{1} \mathrm{H}$ and ${ }^{13} \mathrm{C}$ NMR spectroscopy. ${ }^{13} \mathrm{C}$ NMR (Supporting Information, Figure $\mathrm{S}_{3}$ ) confirmed the introduction of the thioester bond into the copolymer backbone with a signal at $192 \mathrm{ppm}$, characteristic of the thioester functionality (See complete NMR analyses in ESI).

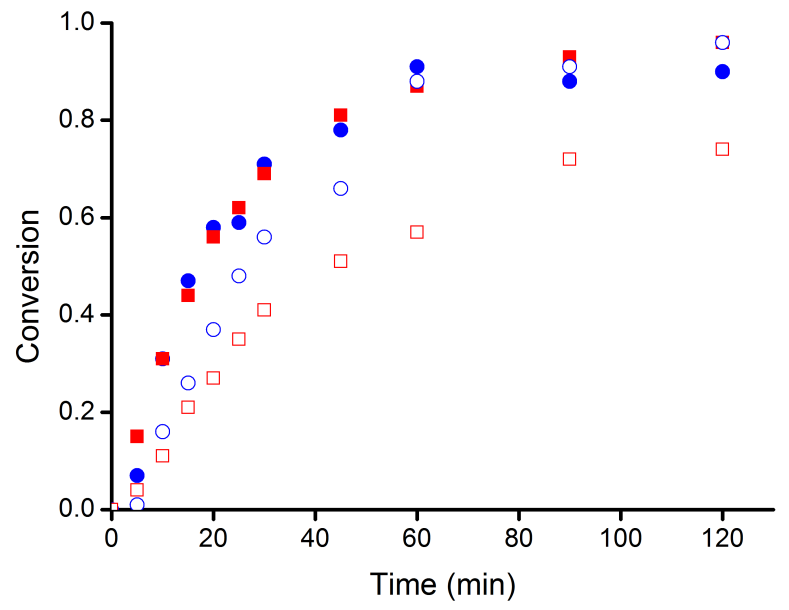

Figure 3. Kinetic plot of the experimental copolymerization of styrene (square) and DOT (dot) at $150^{\circ} \mathrm{C}$ with $80 \mathrm{~mol} \%$ anisole with feed ratio $[\mathrm{S}]_{\mathrm{o}}:[\mathrm{DOT}]_{\mathrm{o}}=95: 5$ (full symbol) and 80 : 20 (empty symbol) initiated with $1 \mathrm{~mol} \%$ of Trigonox 301.
It has to be noted that the characteristic loss of color is also observed in such copolymerization system (Supporting Information, Figure $\mathrm{S}_{4}$ ), originating from the isomerization of the colored $(\mathrm{C}=\mathrm{S})$-O- group after the ring-opening of the thionolactone monomer into a $(\mathrm{C}=\mathrm{O})-\mathrm{S}$ - functionality. The kinetics of the polymerization are reported in Figure 3. Interestingly, and as expected after the PREDICI simulations, the conversion of both monomers are in these conditions rather similar, independently of the initial feed ratio. This indicates a better statistical incorporation of two monomer units into the polymer backbone. As already observed by Gutekunst et al. ${ }^{17}$ with DOT being incorporated slightly faster than tert-butyl acrylate, the experimental incorporation of DOT is also faster compared to styrene, this feature not being expected via the PREDICI simulations.

At the view of these results, we determined the reactivity ratios by fitting the evolution of the feed ratio versus the overall molar conversion (Figure 4), using the Skeist equation and a non-linear least square method (NLLS). ${ }^{20,}{ }^{30,} 31$ This method provides reactivity ratios at $150{ }^{\circ} \mathrm{C}$ of $r_{\mathrm{S}}=0.55$ and $r_{\mathrm{DOT}}=1.68$ with a $r_{\mathrm{sty}} \times r_{\mathrm{DOT}}=0.92$, that is very close to the ideal value of 1 . These values are in accordance with the ones determined via DFT calculations and PREDICI simulations ( $r_{\mathrm{S}}=1.14$ and $\left.r_{\mathrm{DOT}}=0.88\right)$. Despite a slight composition drift at high conversion, a random incorporation of the two monomers was thus demonstrated, which appears essential in the scope of inserting cleavable bonds into the polystyrene backbone. The higher reactivity ratio for the cyclic monomer compared to the vinyl monomer has never been observed and is certainly due to the high rate of radical addition onto the $\mathrm{C}=\mathrm{S}$ group compared to the cyclic ketene acetal group. The reactivity ratios are also totally different from the values determined at $80{ }^{\circ} \mathrm{C}$ by Roth and coworkers ${ }^{16}$ on the methyl acrylate - DOT pair $\left(r_{\mathrm{MA}}=0.424\right.$ and $\left.r_{\mathrm{DOT}}=0.003\right)$.

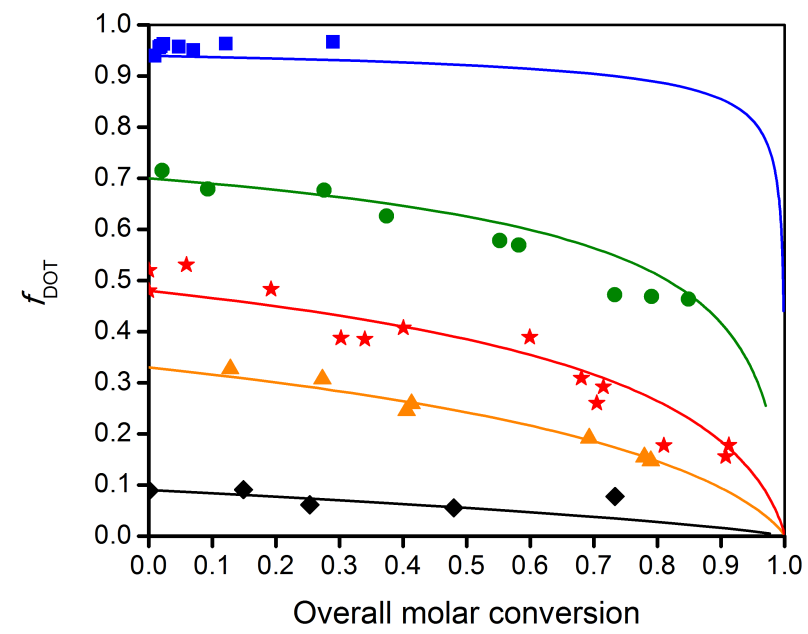

Figure 4. Experimental and theoretical DOT monomer composition versus overall molar conversion with $r_{\mathrm{S}}=0.55$ and $r_{\text {DOT }}=1.68$ during the bulk copolymerization of DOT and Styrene at $150{ }^{\circ} \mathrm{C}$ initiated with $1 \mathrm{~mol} \%$ of Trigonox 301. 


\begin{tabular}{|c|c|c|c|c|c|c|c|c|c|c|}
\hline & $\begin{array}{l}\text { Ratio } \\
\text { S:DOT }\end{array}$ & $\begin{array}{l}\text { Time }(\mathrm{h}) \\
\text { Overall } \\
\text { conversion }\end{array}$ & Initiator & $\begin{array}{l}\text { Anisole } \\
(\mathrm{mol} \%)\end{array}$ & $F_{D O T}$ & $\begin{array}{c}M_{\mathrm{n}} \\
\left(\mathrm{g} \cdot \mathrm{mol}^{-1}\right)\end{array}$ & $\begin{array}{c}M_{\mathrm{w}} \\
\left(\mathrm{g} \cdot \mathrm{mol}^{-1}\right)\end{array}$ & $\theta$ & $\begin{array}{c}\mathrm{T}_{\mathrm{g}} \\
\left({ }^{\circ} \mathrm{C}\right)\end{array}$ & $\begin{array}{l}\mathrm{T}_{5 \%} \\
\left({ }^{\circ} \mathrm{C}\right)\end{array}$ \\
\hline Copo1 & $80: 20$ & $\begin{array}{c}20 \\
0.63\end{array}$ & no & 80 & 31 & 14290 & 28420 & 2 & 94 & 335 \\
\hline PS1 & $100: 0$ & $\begin{array}{l}17 \\
0.8\end{array}$ & no & 80 & - & 45300 & 88400 & 2.2 & 105 & 386 \\
\hline Copo2 & $95: 5$ & $\begin{array}{c}2 \\
0.91\end{array}$ & $\begin{array}{c}\text { TG301 } \\
(1 \mathrm{~mol} \%)\end{array}$ & 80 & 4 & 10700 & 24600 & 2.3 & 91 & 357 \\
\hline PS2 & 100:0 & $\begin{array}{c}2 \\
0.95\end{array}$ & $\begin{array}{c}\text { TG301 } \\
(1 \mathrm{~mol} \%)\end{array}$ & 80 & - & 11400 & 26100 & 2.3 & 93 & 332 \\
\hline Copo3 & $95: 5$ & $\begin{array}{c}17 \\
0.88\end{array}$ & no & 10 & 5 & 74900 & 149900 & 2 & 106 & 357 \\
\hline PS3 & $100: 0$ & $\begin{array}{l}1 \mathrm{~h} 45 \\
0.95\end{array}$ & no & 10 & - & 85000 & 180500 & 2.1 & 107 & 386 \\
\hline
\end{tabular}

Table 4 Experimental conditions used to prepare P(S-co-DOT) copolymer and reference Polystyrene and their thermal properties

These values supposed a tendency to alternating sequences and thus are not in agreement with the degradation profiles presented into the same study.

Copolymers were then prepared at larger scale (about 3-5 g), targeting to obtain high molecular weight materials, at $150{ }^{\circ} \mathrm{C}$ using various polymerization conditions (presence of anisole or thermal initiator, See Copos-3 in Table 4). In all cases, corresponding homopolymers were synthesized in the same conditions (PS1-3).

As expected, the $M_{\mathrm{n}}$ of the obtained copolymers varies with the use of solvent and quantity of initiators (Trigonox 301 or none). The higher $M_{\mathrm{n}}$ is obtained with only $10 \mathrm{~mol} \% \mathrm{sol}-$ vent and without initiator, using only thermal autopolymerization of styrene to initiate polymer chains. It is interesting to note that when using only $5 \mathrm{~mol} \%$ of DOT, the $M_{\mathrm{n}}$ are rather similar to the refence polystyrene (Copoz, PS2, and Copo3, PS3). The main difference relies on the use of an higher $f_{\mathrm{o}, \mathrm{DOT}}=0.2$, that decreases the $M_{\mathrm{n}}$ from 45,300 to 14,300 g.mol ${ }^{-1}$ (Copor). This difference could be ascribed to enhanced termination reaction due to the lower rate of the overall polymerization when high amounts of DOT are used.

\section{Thermal and mechanical properties of $\mathrm{P}$ (S-Co-DOT)}

The glass transition temperatures of PS1-3 and Copo1-3 polymers were analyzed by DSC. As expected, the $T_{\mathrm{g}}$ decreases with the molar masses ${ }^{32}$ but more surprisingly, copolymers containing from 5 to $20 \mathrm{~mol} \%$ DOT display $T_{\mathrm{g}} \mathrm{s}$ with only weak differences ( 1 to $5{ }^{\circ} \mathrm{C}$ ) from their corresponding homopolystyrenes. Thermogravimetric analyses (TGA) show however $5 \%$ degradation temperature $\mathrm{T}_{5} \%$ significantly lower (about 30 to $50^{\circ} \mathrm{C}$ ) for Copos-3 than for the corresponding PS. This interesting feature is consistent with the incorporation of cleavable DOT units with lower chemical stability. The decomposition temperatures remain yet in all cases above $330^{\circ} \mathrm{C}$, which still constitutes an excellent heat resistance for most applications. The thermomechanical properties of high molar mass polymers Copo3 and PS 3 were investigated with Dynamic Mechanical Analysis (DMA) (Figure 5). Both materials displayed extremely similar behaviors, with comparable moduli at room temperature and $T_{\alpha}$ transitions.

Melt rheology was more informative on changes brought by incorporation of DOT units to the viscoelastic properties of the copolymers. To this end, we gathered the frequency-dependent response of small amplitude oscillatory shear (SAOS) over a temperature range from 110 to $190^{\circ} \mathrm{C}$, and constructed the corresponding master curves by timetemperature superposition (TTS) (Figure 6). The large difference in the mastercurves of PS1-3 illustrates, as expected from the corresponding molar masses, a transition from unentangled (PS2) to barely entangled (PS1) and significantly entangled melts (PS3), evidenced by the appearance of an elastic plateau in the storage moduli.

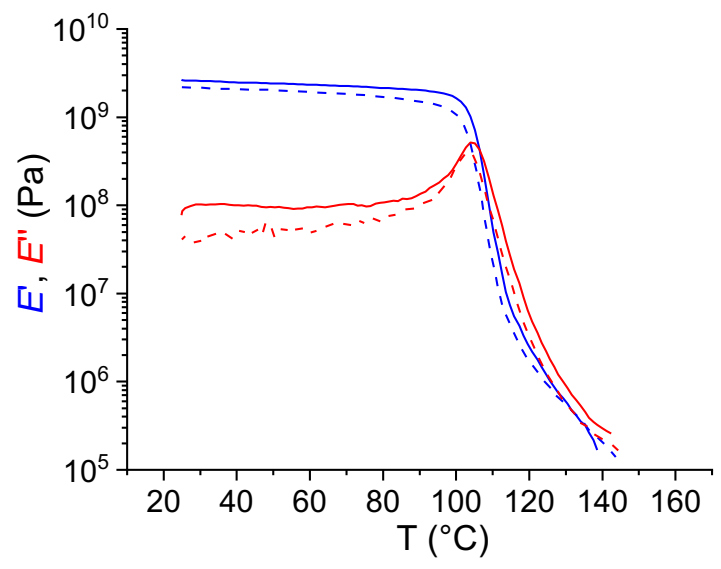

Figure 5. DMA analysis of $\mathbf{P S}_{\mathbf{3}}$ (solid lines) and $\mathrm{Copo}_{3}$ (dashed lines) at $1 \mathrm{~Hz}$ and a heat rate of $3{ }^{\circ} \mathrm{C} \mathrm{min}^{-1}$.

While sample Copo 3 containing 5 mol\% DOT also displays a well entangled regime, it is interesting to note that its 
entanglement modulus $G_{\mathrm{N}}$ (measured at the reduced frequency corresponding to minimal value of $\tan \delta^{33}$ ) is about $140 \mathrm{kPa}$, i.e. significatively lower than that of $\mathrm{PS}_{3}$ (about $190 \mathrm{kPa}$ ). This variation can be related to changes of molecular weight between entanglement, $M_{\mathrm{e}}=G_{\mathrm{N}} /(\rho \mathrm{RT})$. While the obtained $M_{\mathrm{e}}$ value at $T=120{ }^{\circ} \mathrm{C}$ for PS $_{3}$ about 18 $\mathrm{kg} \mathrm{mol}^{-1}$ is in complete agreement with previously reported values, ${ }^{34}$ the higher $M_{\mathrm{e}}$ value about $24 \mathrm{~kg} \mathrm{~mol}^{-1}$ of Copo3 indicates less flexible conformation of the polymer chain, which is consistent with the high rigidity expected from DOT units incorporated the polymer backbone.

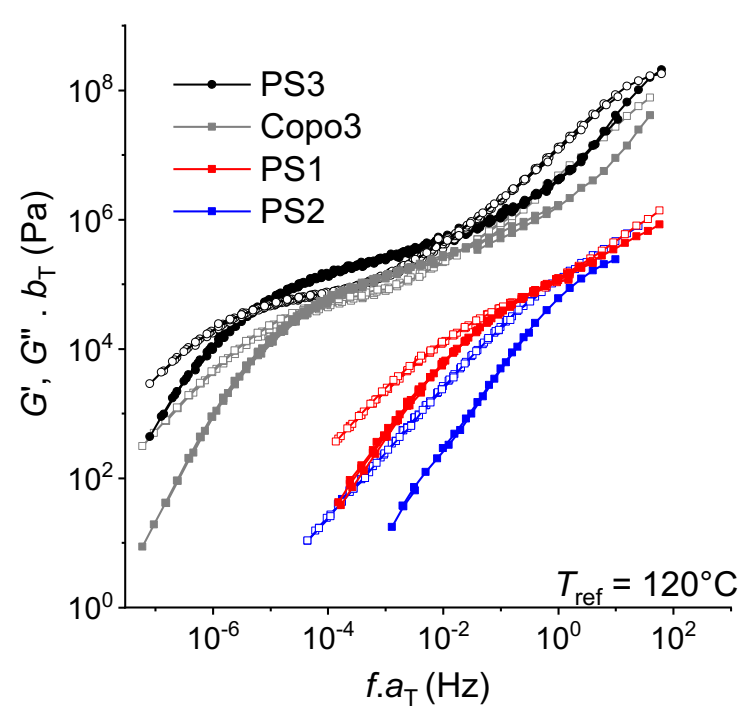

Figure 6. Rheological mastercurves constructed from SAOS analysis of samples PS1-3 and Copo3 and referenced at $T_{\text {ref }}=$ $120^{\circ} \mathrm{C}$. Storage (G') and loss (G”) moduli are shown using solid and open symbols, respectively.

\section{Degradation studies}

Degradation studies of the various copolymers were demonstrated in various conditions. First hydrolysis of PS copolymers in solution was investigated in accelerated conditions by using $5 \mathrm{wt} \%$ potassium hydroxide in THF for $18 \mathrm{~h}$ (Figure 7). In all cases, we observed a strong decrease of the $M_{\mathrm{n}}$ for the degraded products $\left(M_{\mathrm{n}}\right.$ between 900 and 3,ooo g. $\left.\mathrm{mol}^{-1}\right)$. The reference PS (PS1-3) treated in the same conditions did not display any variation of molar mass

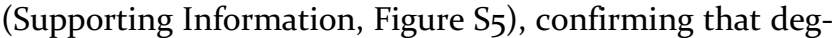
radation occurred by the hydrolysis of the cleavable thioester bonds.

The Copor has a higher amount of DOT (31 mol\%) and thus led to smaller oligomers (900 g.mol $\left.{ }^{-1}\right)$. Copoz and Copos have the same initial feed ratio of DOT (5 mol\%) but the analyses of the isolated copolymer showed a slightly higher incorporation of DOT in Copo3 $5 \mathrm{~mol} \%$ in Copo3 compared to $4 \mathrm{~mol} \%$ in Copoz). This led to a slightly higher $M_{\mathrm{n}}$ for the oligomers (2500 instead of 1600 g.mol ${ }^{-1}$ ). The decomposition of the three copolymers using $\mathrm{KOH}$ showed nevertheless the expected trend, that is, an increase of $M_{\mathrm{n}}$ for the degraded products in the order
Copo2 $>$ Copo3 $>$ Copor that is directly correlated with the fraction of thioester units in the polymer backbone. The more interesting result is the 40 times decrease in molar mass that occurs during the degradation of Copoz. Considering the theoretical incorporation of $5 \mathrm{~mol} \%$ of DOT, we could expect an oligomer with 20 styrene units and a degraded DOT at chain ends. The $M_{\mathrm{n}} / M_{\mathrm{w}}$ of the degraded products are rather close to such oligomer length since 15/30 units were measured. The inaccuracy of theoretical and experimental $M_{\mathrm{n}}$ for such oligomers could be due to the non-negligible chain-end effect on the SEC elution.

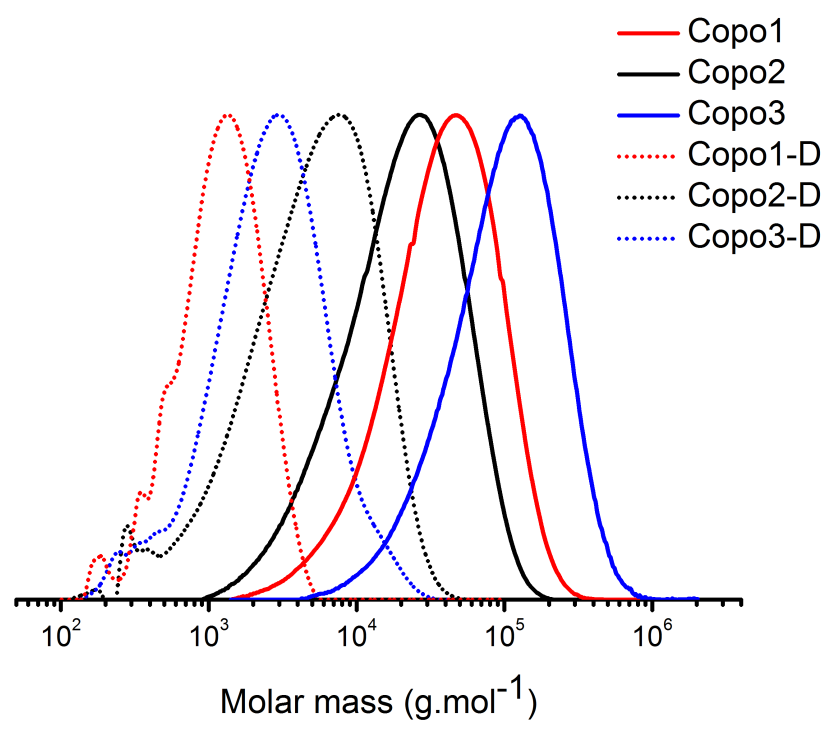

Figure 7. Evolution of the molar mass distribution of the $\mathrm{P}(\mathrm{S}$ co-DOT) after the degradation process $(\mathrm{KOH} 5 \mathrm{wt} \%$ in THF/MeOH during 18 h): Copo3 (blue), Copoz (black), Copor (red),

The kinetics of hydrolysis was monitored and is rather low (18 $\mathrm{h}$ for the complete decomposition, see details in Figure S6) compared to the one reported by Nicolas and coworkers on poly(methyl methacrylate) containing ester units coming from the MPDL CKA copolymerization where degradation in similar conditions lasted only minutes. ${ }^{35}$ The kinetics of decomposition is then comparable with the duration that is described by Thoniyot and Van Herk ${ }^{14}$ for the degradation of their polystyrene containing ester units.

Other degradations conditions were also tested as discussed previously. First, aminolysis using $\mathrm{N}$-isopropylamine in dichloromethane as already reported ${ }^{16}$ were still unable to degrade the copolymers (See ESI for details). We thus tried various amines with different steric hindrance such has ethanolamine or even ammonia in THF but without success. Similarly, we tried the heterogeneous degradation of the polystyrene in basic water also without success.

Lastly, we investigated organic acids and bases to induce degradation. Addition of organic acids such as trifluoroacetic acid (TFA) or para-toluene sulfonic acid (PTSA) in THF (2.5 wt\%) did not trigger important changes (Supporting information, Figure $S_{7}$ ). While 1,8-diazabicyclo[5.4.0]undec-7-ene (DBU) in THF was recently found 
very efficient to degrade polythioesters ${ }^{36}$ our tests in similar conditions showed again very little effect (Figure 8).

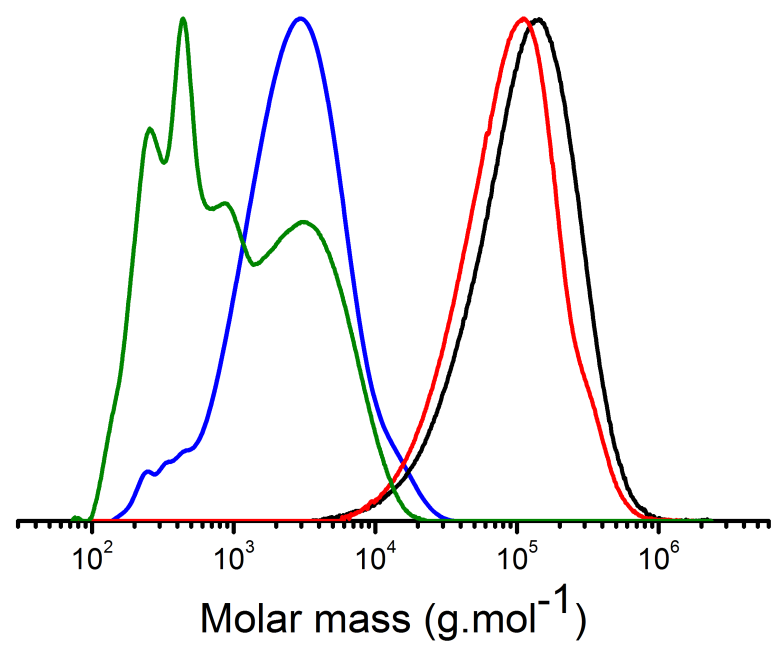

Figure 8. Evolution of the molar mass distribution of $\mathrm{P}(\mathrm{S}-\mathrm{co}-$ DOT) during the degradation process: Copoz before degradation (dark), Copo3 after $17 \mathrm{~h}$ of degradation using DBU (red), Copo3 after $18 \mathrm{~h}$ of degradation using $\mathrm{KOH}$ (blue), Copo3 after ih of degradation using TBD (green).

Other strong organic bases such as TBD were however much more efficient, leading to a very rapid and complete decomposition of the thioester moieties achieving oligomers of $M_{\mathrm{n}}=600 \mathrm{~g} \cdot \mathrm{mol}^{-1}$ and $M_{\mathrm{w}}=1,950 \mathrm{~g} \cdot \mathrm{mol}^{-1}$ for the degradation of Copo3. This very low $M_{\mathrm{n}}$ compared to the theoretical one (2200 g. $\left.\mathrm{mol}^{-1}\right)$ could be due to the non-linearity of the calibration curve at such low molecular weight but also in the presence of residual TBD that cannot be separated of such small oligomers.

In order to analyze with a faster time-resolution the quick degradation of the copolymers by TBD, we set-up an insitu rheology experiment using a Couette cell (volume 5 $\mathrm{mL}$ ) and concentrated polymer solutions (20 wt $\%)$, The evolution of the specific viscosity $\eta_{\mathrm{sp}}$ was monitored upon addition of a concentrated TBD solution in THF (overall concentration $1.25 \mathrm{wt} \%$ ) and thorough mixing (Figure 9).

While no significant differences upon addition of TBD can be seen on PS $_{3}$ solutions, the decrease of viscosity starts readily for Copoz solutions. Based on the final values of viscosities obtained after $2.5 \mathrm{~h}$, the $90 \%$ decrease is obtained in less than $20 \mathrm{~min}$.

Finally, PS 3 and Copo3 were tested for bacterial degradation. As said previously, the biodegradation of polystyrene has been investigated using a wide range of fungi, microbes and invertebrates. ${ }^{6,37}$ According to literature data and the availability of the various bacteria, Pseudomonas aeruginosa and Aspergilus niger were selected. ${ }^{38,39}$ The two polystyrenes were then incubated as powders with the bacteria in a culture medium without carbon source. To monitor the antimicrobial activity, we chose to use microcalorimetry. This technique has been shown to serve as an indirect measurement of a particular bioactivity that is not easily measurable in complex biosystems and bioprocesses. ${ }^{40}$ Moreover, the high degree of sensitivity, precision and accuracy of this technique is interesting to observe very small change between reference $\mathrm{PS}_{3}$ and $\mathrm{Copo}_{3}$. The experiments are detailed in ESI. After $7 \mathrm{O}$ h, the Copo3 presented a slightly higher activity than the reference $\mathbf{P S}_{\mathbf{3}}$ (Figure S8), which shows premises for the degradation of such materials. The complete study focusing on the bacterial degradation of $\mathrm{p}(\mathrm{S}-\mathrm{co}-\mathrm{DOT})$ copolymers will be further detailed in a subsequent article.

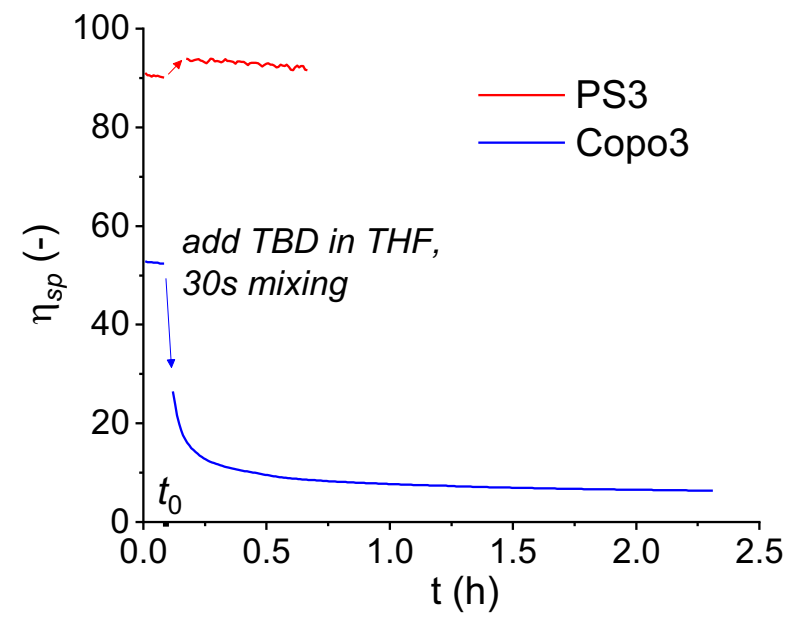

Figure 9. Evolution of specific viscosity of solutions of $\mathbf{P S}_{3}$ and $\mathbf{C o p o} 3$ in THF (20 wt\%) upon addition of concentrated TBD solution in THF leading to an overall TBD concentration of $1.25 \mathrm{wt} \%$.

\section{Triggered degradation}

The efficient degradation of $\mathrm{p}(\mathrm{S}-\mathrm{co}-\mathrm{DOT})$ copolymers in presence of TBD is a good promise for the controlled degradation of polystyrene materials. Indeed, such degradation as shown previously is very fast after the introduction of the organic base. To selectively trigger the degradation, we sought to prepare a photolatent TBD also known as photobase generator. ${ }^{41}$ Usually, these compounds are quaternary ammonium salts that generate, upon irradiation, the corresponding amine after a decarboxylation process ${ }^{41}$ (Figure 1ob). As a proof of concept, we prepared the TBD ammonium salt of phenylglyoxylic acid in one straightforward step, following an adapted procedure ${ }^{42}$ (Figure 10a).

The photolatent TBD ( $4 \mathrm{wt} \%$ to mimic $2 \mathrm{wt} \% \mathrm{TBD}$ ) and Copo3 was then mixed in THF at room temperature and analyzed by SEC $120 \mathrm{~h}$ later. The results are presented in Figure $10 \mathrm{c}$ and confirmed the non-degradation of the Copo3 with the protected TBD.

The THF solution was then irradiated using a mercury lamp for 10 times $2.5 \mathrm{~min}$ with hand shaking between the irradiations and analyzed by SEC one hour later. As expected, the base was released and led to the degradation of the Copoz, confirming the efficiency of the controlled degradation. This approach open the way to a new procedure to both keep the usage materials properties of a product 
and thus accelerated its degradation after use by irradiation. Phenylglyoxylic acid has a strong absorption at 254 $\mathrm{nm}$ and thus required to use a mercury lamp. Chromophores absorbing at higher wavelength will be needed to improve the irradiation but this result open the way for a triggered degradation with such polymers.

a)

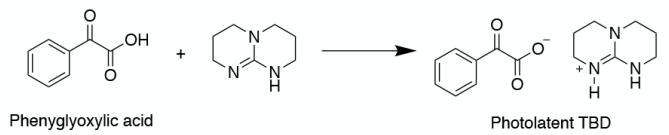

b)

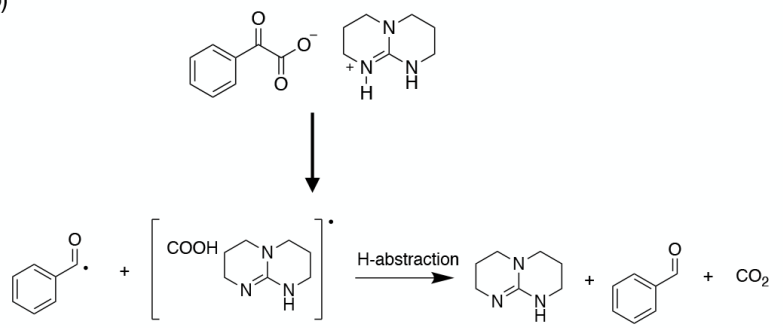

c)

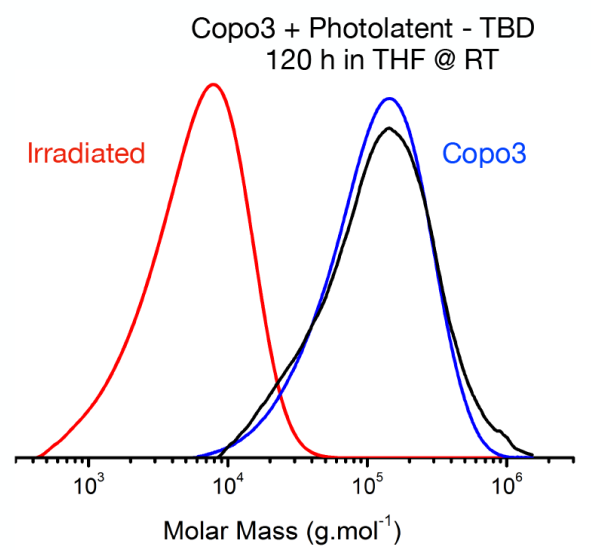

Figure 10. a) Synthesis of the photolatent - TBD. b) Deprotection mechanism of the Photolatent - TBD upon irradiation. c) Evolution of the molar mass distribution of the $\mathrm{Copos}_{3} \mathrm{P}\left(\mathrm{S}-\mathrm{co}^{-}\right.$ DOT) in THF (blue), after mixing with Photolatent - TBD (2 $\mathrm{wt} \%$ ) during $120 \mathrm{~h}$ at RT (black) and after 10 times $2.5 \mathrm{~min}$ of irradiation and one hour of reaction.

\section{Cross-linked polystyrene}

Besides linear polystyrene chains, polystyrene has been also widely used in cross-linked materials thanks to straightforward radical copolymerization with divinyl benzene. Such cross-linked polymers have notably found applications as supports for polymer-bound reagents and catalysts, ion exchange resins and separation media. ${ }^{43^{-45}} \mathrm{Re}-$ cently, Johnson and coworkers ${ }^{46}$ reported that the incorporation of a small amount of cleavable bond into the linear segments of a network afforded very efficient degradability (Figure 11). Building upon this concept, cross-linked poly(S-co-DOT) networks were prepared via the copolymerization at $150^{\circ} \mathrm{C}$ of styrene : divinyl benzene : DOT mixtures with molar ratios of $94: 1: 5$. A non-cleavable network was also prepared for comparison purposes with molar ratios of styrene : divinyl benzene of $99: 1$. At the end of the polymerization we obtained cross-linked solid polystyrene pellets (Figure 11a). When DOT was incorporated inside the materials, the orange/yellow color was maintained due to the non-complete conversion of all monomers during the reaction. Extensive washings were performed using acetone to remove the unreacted DOT to the thermoset, but a pale-yellow color still remained. Both reference thermoset and the DOT-containing one were then degraded in THF using both TBD and $5 \mathrm{w} \% \mathrm{KOH}$. In both cases, the reference thermoset was not degraded and did not lose weight whereas the thermoset containing DOT led to opaque solution without any remaining solid materials (Figure $11 \mathrm{~b}$ ). The TBD degradation is far more effective than the one using $\mathrm{KOH}$ due to solubility issues. This result demonstrates that a small amount of DOT ( $5 \mathrm{~mol} \%$ ) is thus efficient to allow the complete degradation of cross-linked polystyrene.

\section{CONCLUSION}

Thionolactones have been recently reported to be a new promising family of monomers able to undergo radical ring-opening. It was especially noted that the copolymerization of DOT with styrene was unsuccessful. In this article, we first reinvestigated in details the copolymerization of DOT and styrene and we showed that, contrary to what was claimed in the literature, DOT could be incorporated into the PS backbone but with a lower reactivity that led to roughly half of the initial feed ratio inserted. We thus performed some DFT calculations coupled with PREDICI simulation that suggested to increase the reaction temperature to allow a better randomly incorporation of the DOT unit into the PS backbone. The copolymerization was thus carried out at $150{ }^{\circ} \mathrm{C}$ using either Trigonox 301 or the thermal auto-initiation of styrene. The insertion of both monomers was then measured and led to reactivity ratios of $r_{\mathrm{S}}$ $=0.55$ and $r_{\text {DOT }}=1.68$ with a $r_{\text {sty }} \times r_{\text {DOT }}=0.92$, showed $\mathrm{a}$ more statistical incorporation of DOT inside the polymer chains. Using this temperature, a high molecular weight PS containing $5 \mathrm{~mol} \%$ of DOT was then obtained that presented similar thermal and mechanical properties than the reference PS. These copolymers were then degraded and showed peculiar degradation conditions: they are rather stable in acidic conditions, impervious to aminolysis regardless of the primary amine used but presented a good degradation profile when strong bases such as $\mathrm{KOH}$ or TBD are used. In the latter case, total degradation in less than one hour was observed.

The use of TBD let us envision a controlled degradation using a photolatent-TBD compound based on the phenylglyoxylic acid chromophore. The proof of concept was demonstrated in solution. Lastly, we also extent this work to cross-linked polystyrene. The solid pellets coming from the introduction of a small amount of divinylbenzene could be made soluble by the introduction of $5 \mathrm{~mol} \%$ of DOT in the initial recipe followed by a degradation using either TBD or $\mathrm{KOH}$.

In summary, this article showed that the use of 5 mol DOT as a comonomer in an industrial-scalable recipe leads to a material that are similar properties (molecular weight, 
thermal, mechanical, etc.) than polystyrene but that could be degraded in oligomers with less than 10 units long after a mild chemical treatment

a)

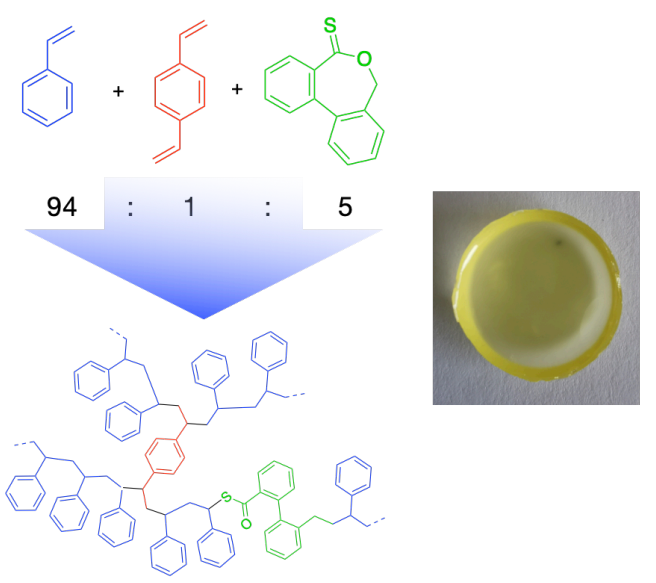

b)

THF/MeOH - 5 wt\% KOH 12 days

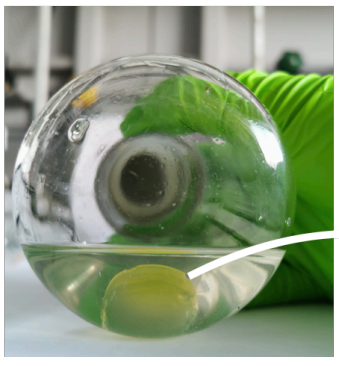

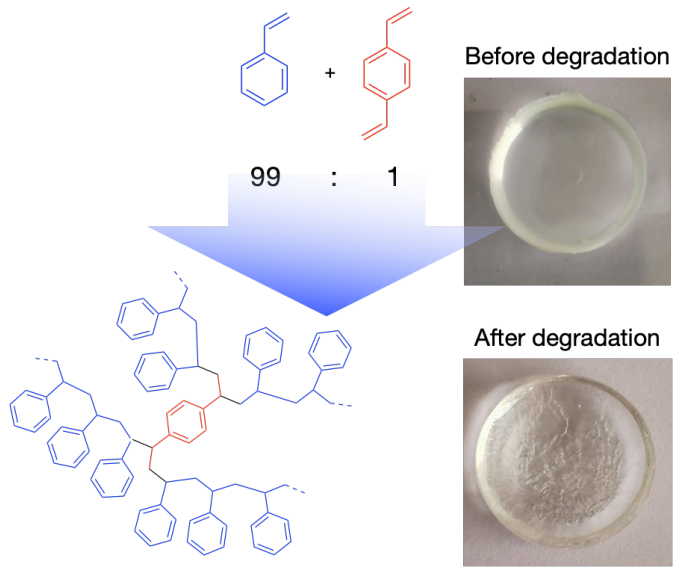

THF - 2.5 wt \% TBD 17h
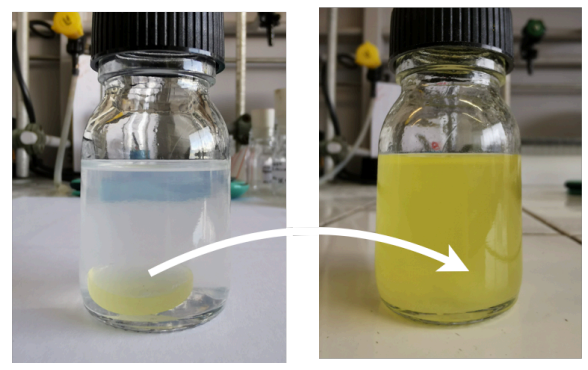

Figure 11. a) Preparation of cross-linked polystyrene using $1 \mathrm{~mol} \%$ of divinylbenzene with and without $5 \mathrm{~mol} \%$ of DOT. b) Degradation of the $\mathrm{P}(\mathrm{S}-\mathrm{co}-\mathrm{DOT})$ thermoset either using $\mathrm{KOH}(5 \mathrm{~mol} \%$ in THF/MeOH) or $2.5 \mathrm{wt} \% \mathrm{TBD}$ in THF.

\section{ASSOCIATED CONTENT}

\section{Supporting Information}

The Supporting Information is available free of charge on the ACS Publications website. ${ }^{1} \mathrm{H}$ NMR and ${ }^{13} \mathrm{C}$ NMR spectra of the various polymers, kinetic rate constants used in the modeling part,

\section{AUTHOR INFORMATION}

\section{Corresponding Author}

Catherine.lefay@univ-amu.fr ; yohann.guillaneuf@univ-amu.fr

\section{Author Contributions}

The manuscript was written through contributions of all authors.

\section{ACKNOWLEDGMENT}

We thank the French National Research Agency (ANR-18CEo6-oo14. This work was also supported by the 'Centre Régional de Compétences en Modélisation Moléculaire de Marseille'.

\section{REFERENCES}

1. Gutiérrez, C.; Rodríguez, J. F.; Gracia, I.; de Lucas, A.; García, M. T., Reduction of the carbon footprint through polystyrene recycling: Economical evaluation. Process Safety and Environmental Protection 2016, 101, 144-151.

2. Miandad, R.; Nizami, A. S.; Rehan, M.; Barakat, M. A.; Khan, M. I.; Mustafa, A.; Ismail, I. M. I.; Murphy, J. D., Influence of temperature and reaction time on the conversion of polystyrene waste to pyrolysis liquid oil. Waste Manag 2016, 58, 250-259.

3. Dement'ev, K. I.; Palankoev, T. A.; Alekseeva, O. A.; Babkin, I. A.; Maksimov, A. L., Thermal depolymerization of polystyrene in highly aromatic hydrocarbon medium. Journal of Analytical and Applied Pyrolysis 2019, 142.

4. Gutiérrez, C.; García, M. T.; Gracia, I.; Lucas, A.; Rodríguez, J. F., Recycling of extruded polystyrene wastes by dissolution and supercritical $\mathrm{CO}_{2}$ technology. Journal of Material Cycles and Waste Management 2012, 308-316.

5. $\quad$ Cella, R. F.; Mumbach, G. D.; Andrade, K. L.; Oliveira, P.; Marangoni, C.; Bolzan, A.; Bernard, S.; Machado, R. A. F., Polystyrene recycling processes by dissolution in ethyl acetate. Journal of Applied Polymer Science 2018, 135 (18), 46208.

6. Ho, B. T.; Roberts, T. K.; Lucas, S., An overview on biodegradation of polystyrene and modified polystyrene: the microbial approach. Crit Rev Biotechnol 2018, 38 (2), 308-320. 7. $\quad$ Peng, B. Y.; Su, Y.; Chen, Z.; Chen, J.; Zhou, X.; Benbow, M. E.; Criddle, C. S.; Wu, W. M.; Zhang, Y., Biodegradation of Polystyrene by Dark ( Tenebrio obscurus) and 
Yellow ( Tenebrio molitor) Mealworms (Coleoptera: Tenebrionidae). Environ Sci Technol 2019, 53 (9), 5256-5265.

8. Yang, S. S.; Brandon, A. M.; Andrew Flanagan, J. C.; Yang, J.; Ning, D.; Cai, S. Y.; Fan, H. Q.; Wang, Z. Y.; Ren, J.; Benbow, E.; Ren, N. Q.; Waymouth, R. M.; Zhou, J.; Criddle, C. $\mathrm{S}$.; $\mathrm{Wu}, \mathrm{W}$. M., Biodegradation of polystyrene wastes in yellow mealworms (larvae of Tenebrio molitor Linnaeus): Factors affecting biodegradation rates and the ability of polystyrene-fed larvae to complete their life cycle. Chemosphere 2018, 191, 979989.

9. Tardy, A.; Nicolas, J.; Gigmes, D.; Lefay, C.; Guillaneuf, Y., Radical Ring-Opening Polymerization: Scope, Limitations and Application to (Bio)Degradable Materials. Chem. Rev. 2017, 117, 1319-1406.

10. Agarwal, S., Chemistry, chances and limitations of the radical ring-opening polymerization of cyclic ketene acetals for the synthesis of degradable polyesters. Polym. Chem. 2o10, 1, 953964 .

11. Bailey, W. J.; Ni, Z.; Wu, S. R., Synthesis of poly-epsiloncaprolactone via a free-radical mechanism - free-radical ringopening polymerization of 2-methylene-1,3-dioxepane. Journal of Polymer Science Part a-Polymer Chemistry 1982, 20 (11), 3021-3030. 12. Bailey, W. J.; Endo, T.; Gapud, B.; Lin, Y. N.; Ni, Z.; Pan, C. Y.; Shaffer, S. E.; Wu, S. R.; Yamazaki, N.; Yonezawa, K., Synthesis of functionally-terminated oligomers by free-radical ring-opening polymerization. Journal of Macromolecular ScienceChemistry 1984, A21 (8-9), 979-995.

13. Wickel, H.; Agarwal, S., Synthesis and Characterization of Copolymers of 5,6-Benzo-2-methylene-1,3-dioxepane and Styrene. Macromolecules 2003, 36 (16), 6152-6159.

14. Jackson, A. W.; Reddy Mothe, S.; Chennamaneni, L. R.; van Herk, A.; Thoniyot, P., Unraveling the History and Revisiting the Synthesis of Degradable Polystyrene Analogues via Radical Ring-Opening Copolymerization with Cyclic Ketene Acetals. Materials (Basel) 2020, 13 (10).

15. $\quad$ Gigmes, D.; Van Steenberge, P. H. M.; Siri, D.; D'Hooge D, R.; Guillaneuf, Y.; Lefay, C., Simulation of the Degradation of Cyclic Ketene Acetal and Vinyl-Based Copolymers Synthesized via a Radical Process: Influence of the Reactivity Ratios on the Degradability Properties. Macromol Rapid Commun 2018, 39 (19), e180o193.

16. Bingham, N. M.; Roth, P. J., Degradable vinyl copolymers through thiocarbonyl addition-ring-opening (TARO) polymerization. Chem Commun (Camb) 2018, 55 (1), 55-58.

17. Smith, R. A.; Fu, G.; McAteer, O.; Xu, M.; Gutekunst, W. R., Radical Approach to Thioester-Containing Polymers. J Am Chem Soc 2019, 141 (4), 1446-1451.

18. Bingham, N. M.; Nisa, Q. U.; Chua, S. H. L.; Fontugne, L.; Spick, M. P.; Roth, P. J., Thioester-Functional Polyacrylamides: Rapid Selective Backbone Degradation Triggers Solubility Switch Based on Aqueous Lower Critical Solution Temperature/Upper Critical Solution Temperature. Acs Applied Polymer Materials 2020, 2 (8), 3440-3449.

19. Tardy, A.; Gil, N.; Plummer, C. M.; Siri, D.; Gigmes, D.; Lefay, C.; Guillaneuf, Y., Polyesters by a Radical Pathway: Rationalization of the Cyclic Ketene Acetal Efficiency. Angew Chem Int Ed Engl 2020, 59 (34), 14517-14526.

20. Tardy, A.; Honore, J. C.; Tran, J.; Siri, D.; Delplace, V.; Bataille, I.; Letourneur, D.; Perrier, J.; Nicoletti, C.; Maresca, M.; Lefay, C.; Gigmes, D.; Nicolas, J.; Guillaneuf, Y., Radical Copolymerization of Vinyl Ethers and Cyclic Ketene Acetals as a Versatile Platform to Design Functional Polyesters. Angew Chem Int Ed Engl 2017, 56 (52), 16515-16520.

21. Tardy, A.; Gil, N.; Plummer, C. M.; Zhu, C.; Harrisson, S.; Siri, D.; Nicolas, J.; Gigmes, D.; Guillaneuf, Y.; Lefay, C., DFTcalculation-assisted prediction of the copolymerization between cyclic ketene acetals and traditional vinyl monomers. Polymer Chemistry 2020, 11 (45), 7159-7169.

22. Tardy, A.; Honoré, J.-C.; Siri, D.; Nicolas, J.; Gigmes, D.; Lefay, C.; Guillaneuf, Y., A comprehensive kinetic study of the conventional free-radical polymerization of seven-membered cyclic ketene acetals. Polymer Chemistry 2017, 8 (34), 5139-5147.

23. Keddie, D. J.; Moad, G.; Rizzardo, E.; Thang, S. H., RAFT Agent Design and Synthesis. Macromolecules 2012, 45 (13), 5321-5342.

24. Lin, C. Y.; Izgorodina, E. I.; Coote, M. L., How accurate are approximate methods for evaluating partition functions for hindered internal rotations? Journal of Physical Chemistry A 20o8, 112 (9), 1956-1964.

25. Fischer, H.; Radom, L., Factors Controlling the Addition of Carbon-Centered Radicals to Alkenes-An Experimental and Theoretical Perspective. Angewandte Chemie International Edition 2001, 40 (8), 1340-1371.

26. Barclay, L. R. C.; Griller, D.; Ingold, K. U., Kinetic applications of Electron Paramagnetic Resonance Spectroscopy. 38. Rearrangement of b-(Acyloxy)alkyl and b-(Benzoyloxy)alkyl radicals. Journal of the American Chemical Society 1982, 104, 43994403 .

27. Benson, S. W., Thermochemical Kinetics. Wiley: New York, 1976.

28. Ranieri, K.; Delaittre, G.; Barner-Kowollik, C.; Junkers, T., Direct Access to Dithiobenzoate RAFT Agent Fragmentation Rate Coefficients by ESR Spin-Trapping. Macromolecular Rapid Communications 2014, 35 (23), 2023-2028.

29. Wulkow, M., Macromolecular Reaction Engineering 2008, 2, 461-494.

30. Vanherk, A. M., Least-Squares Fitting by Visualization of the Sum of Squares Space. Journal of Chemical Education 1995, $72(2), 138-140$.

31. vanHerk, A. M.; Droge, T., Nonlinear least squares fitting applied to copolymerization modeling. Macromol. Theory Simul. 1997, 6 (6), 1263-1276.

32. Claudy, P.; Letoffe, J. M.; Camberlain, Y.; Pascault, J. P., Glass-transition of polystyrene versus molecular-weight. Polymer Bulletin 1983, 9 (4-5), 208-215.

33. Liu, C. Y.; He, J. S.; van Ruymbeke, E.; Keunings, R.; Bailly, C., Evaluation of different methods for the determination of the plateau modulus and the entanglement molecular weight. Polymer 2006, 47 (13), 4461-4479.

34. Fetters, L. J.; Lohse, D. J.; Milner, S. T.; Graessley, W. W., Packing length influence in linear polymer melts on the entanglement, critical, and reptation molecular weights. Macromolecules 1999, 32 (20), 6847-6851.

35. Guegain, E.; Michel, J. P.; Boissenot, T.; Nicolase, J., Tunable Degradation of Copolymers Prepared by NitroxideMediated Radical Ring-Opening Polymerization and Point-byPoint Comparison with Traditional Polyesters. Macromolecules 2018, 51 (3), 724-736.

36. Yuan, J.; Xiong, W.; Zhou, X.; Zhang, Y.; Shi, D.; Li, Z.; Lu, H., 4-Hydroxyproline-Derived Sustainable Polythioesters: Controlled Ring-Opening Polymerization, Complete Recyclability, and Facile Functionalization. J Am Chem Soc 2019, 141 (12), 4928-4935.

37. Kim, H. R.; Lee, H. M.; Yu, H. C.; Jeon, E.; Lee, S.; Li, J.; Kim, D. H., Biodegradation of Polystyrene by Pseudomonas sp. Isolated from the Gut of Superworms (Larvae of Zophobas atratus). Environ Sci Technol 2020, 54 (11), 6987-6996.

38. Lee, H. M.; Kim, H. R.; Jeon, E.; Yu, H. C.; Lee, S.; Li, J.; Kim, D. H., Evaluation of the Biodegradation Efficiency of Four Various Types of Plastics by Pseudomonas aeruginosa Isolated from the Gut Extract of Superworms. Microorganisms 2020, 8 (9), 1341. 
39. Asmita, K.; Shubhamsingh, T.; Tejashree, S., Isolation of Plastic Degrading Micro-organisms from Soil Samples Collected at Various Locations in Mumbai, India. International Research Journal of Environmental Sciences 2015, 4, 77-85.

40. Fradette, S.; Rho, D.; Samson, R.; Leduy, A. Microcalorimetry as a diagnostic and analytical tool for the assessment of biodegradation of 2,4-d in a liquid-medium and in soil. Applied Microbiology and Biotechnology 1994, 42 (2-3), 432439.

41. Zivic, N.; Kuroishi, P. K.; Dumur, F.; Gigmes, D.; Dove, A. P.; Sardon, H., Recent Advances and Challenges in the Design of Organic Photoacid and Photobase Generators for Polymerizations. Angewandte Chemie-International Edition 2019, 58 (31), 10410-10422.

42. Salmi, H.; Allonas, X.; Ley, C.; Defoin, A.; Ak, A., Quaternary ammonium salts of phenylglyoxylic acid as photobase generators for thiol-promoted epoxide photopolymerization. Polymer Chemistry 2014, 5 (22), 6577-6583.

43. Antony, A.; Ajil, P. A.; Varkey, J. T. In 1, 6-Hexanediol Diacrylate Cross-linked Polystyrene-A novel catalyst support system-Its synthesis, swelling capacity studies and surface morphological analysis, APRM Conference, Palawan,
PHILIPPINES, May 28-Jun 02; Palawan, PHILIPPINES, 2018; pp 105-110.

44. Arashima, J.; Iwai, T.; Sawamura, M., A PolystyreneCross-Linking Tricyclohexylphosphine: Synthesis, Characterization and Applications to Pd-Catalyzed CrossCoupling Reactions of Aryl Chlorides. Chemistry-an Asian Journal 2019, 14 (3), 411-415.

45. Zhang, X.; Shen, S. H.; Fan, L. Y., Studies progress of preparation, properties and applications of hyper-cross-linked polystyrene networks. Journal of Materials Science 2007, 42 (18), 7621-7629.

46. Shieh, P.; Zhang, W.; Husted, K. E. L.; Kristufek, S. L.; Xiong, B.; Lundberg, D. J.; Lem, J.; Veysset, D.; Sun, Y.; Nelson, K. A.; Plata, D. L.; Johnson, J. A., Cleavable comonomers enable degradable, recyclable thermoset plastics. Nature 2020, 583, 542547 . 


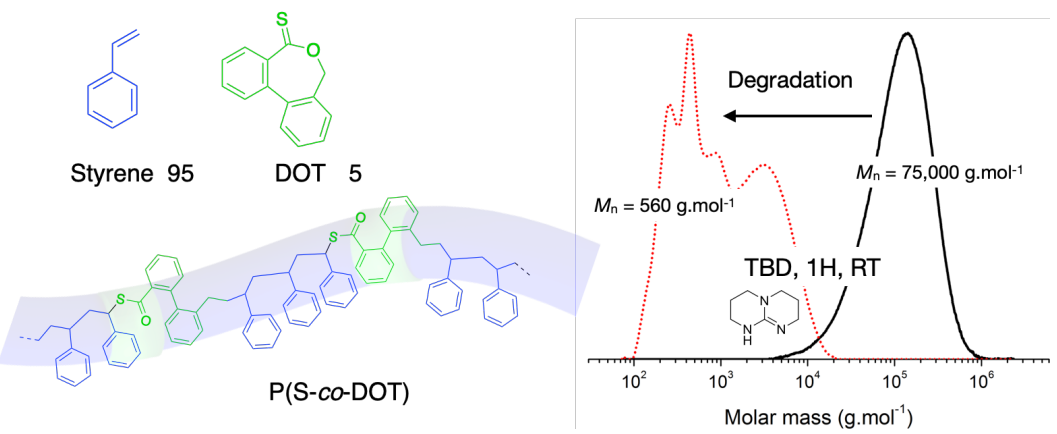

